\title{
Facile and green synthesis of nitrogen-doped polymer and carbon porous spheres
}

\author{
Amandine Maetz, Luc Delmotte, Georges Moussa, Joseph Denzer, Stephan Knopf, Camelia Matei \\ Ghimbeu*
}

\author{
${ }_{5}$ Received (in $\left.X X X, X X X\right)$ Xth $X X X X X X X X X 20 X X$, Accepted Xth $X X X X X X X X X 20 X X$ \\ DOI: 10.1039/b000000x
}

\begin{abstract}
The development of green, sustainable and simple synthesis pathways for the design of polymer and carbonaceous materials with well controlled features is of great importance for many fields of applications. Herein, we report a green synthesis method for polymer and 10 carbon particles with well-defined shape and size. This approach involves the use of green precursors, water as solvent, no templates under ambient temperature and pressure conditions, simultaneously. Green polymer resins (phloroglucinol-glyoxylic acid) and a catalyst/nitrogen source (triethylenediamine) are dissolved in water at room temperature resulting in polymer particles which by subsequent thermal treatment transforms in carbon particles. Mainly spherical carbon particles with controlled size from $500 \mathrm{~nm}$ to 10 $\mu \mathrm{m}$ were obtained by simply adjusting the experimental conditions, i.e., the synthesis time and the molar ratio between the precursors or 15 solvent. In some conditions, flower-like morphology was obtained as well. The synthesis mechanism from polymer resin spheres formation to their conversion into carbon sphere was determined by several techniques, i.e., ${ }^{13} \mathrm{C}$ NMR spectroscopy, SEM, XPS and TPD-MS (temperature programmed desorption coupled by mass spectrometer).
\end{abstract}

\section{INTRODUCTION}

Nanostructured carbon materials with controlled texture, structure, morphology and surface chemistry witness a large

25 pallet of utilizations such as absorbents, electrodes for batteries and supercapacitors, catalyst, fuel cells or gas sensors ${ }^{1-6}$. Particularly, nanoporous carbon spheres have considerably attracted attention in the recent years due to their tunable particle size/shape, improved pore accessibly providing faster molecular 30 diffusion and specific structure containing open edges inducing specific reactivity with molecules ${ }^{2 ; 7 ; 8}$.

Several synthetic approaches have been proposed during the time to design carbon spheres with different particle sizes, tunable pore size/geometry and graphitization levels. Firstly, chemical

35 vapor deposition (CVD) routs were employed, involving the thermal pyrolysis of hydrocarbons (toluene, benzene, hexane, methane, acetylene etc.) at high temperature $\left(600^{\circ} \mathrm{C}\right.$ to $\left.1200^{\circ} \mathrm{C}\right)$ in the presence or not of a metallic-based catalyst ${ }^{7}$. Such approach allows to obtain graphitic carbon spheres but uniform 40 particles is difficult to be achieved. In addition, the inconvenient including high temperature reactions, toxic and dangerous carbon precursors and sacrificial use of catalyst limited the extensive use of such approach.

Hard-templating pathways involves the use of silica or latex 45 particles which are filled with carbon precursors by wet impregnation or by CVD with hydrocarbon gases. This step is followed by the dissolution of the template with strong acids or bases allowed to obtain well defined carbon spheres with controlled ordered porosity ${ }^{9 ; 10}$. The obtained carbon spheres 50 correspond to the negative replicas of silica/latex spheres. Despite the good control of carbon spheres characteristics obtained by hard-template, the long synthesis process related to the preparation of hard templates and their dissolution with hazardous $\mathrm{HF}$ or $\mathrm{NaOH}$ are considered as the main drawbacks of 55 this approach.
More recently, the soft-template route emerged as an alternative approach. Commercially available block copolymer soft templates easily decomposable thermally are being used as pore and structure directing agents together with thermosetting 60 polymers resins as carbon source under hydrothermal conditions. Carbon spheres with well controlled mesoporosity were achieved only in few cases and their preparation remains a challenge ${ }^{11 ; 12}$ Besides, the low carbon yield, high cost and restrained choice of templates are important issues to be overcome.

${ }_{65}$ Hydrothermal route carbonization route (HTC) in aqueous medium at low temperatures $\left(<300^{\circ} \mathrm{C}\right)$ and under pressure $(\sim 1$ $\mathrm{MPa}$ ) was found to be a sustainable and efficient process to transform sugar-based precursors (glucose, fructose, cellulose, biomass etc.) into carbon spheres, without the use of templates ${ }^{13-}$ 7015 .

However, such carbons are obtained with low yield and present limited porosity, therefore, supplementary additives or post activation treatments are required in order to adjust the porosity ${ }^{16-}$ 18 .

75 A significant progress in the preparation of carbon spheres was recently achieved by modification of Stöber method ${ }^{19 ; 20}$. Originally developed for the preparation of silica particles by a sol-gel reaction under hydrothermal conditions, it has been demonstrated that this method can be extended to the preparation 80 of monodisperse phenolic-resin polymer spheres and therefore, by thermal decomposition for carbon spheres preparation. Phenolic-resins are of great interest due to their high thermal stability and high carbon yield useful for practical application. Mainly, phenol-formaldehyde based resins are used 21-23, 85 although these precursors are highly toxic and/or carcinogen. As alternative to these toxic precursors we have recently proposed green resins based on phloroglucinol and glyoxylic acid in order to prepared mesoporous carbons powders and films ${ }^{24}$.

In addition to the toxic precursors often used in the Stöber 90 method, non-aqueous solvents and hydrothermal treatments $(60$ to $220^{\circ} \mathrm{C}$ ) are required to obtain carbon spheres. Another 
important key of the Stöber synthesis is the catalyst employed which will direct the particle morphology and size. Ammonium hydroxide is usually employed in such synthesis but its pungent smell and its toxicity for environment direct researchers to 5 evaluate novel catalysts. Song et al. ${ }^{25}$ proposed the use of urea in this aim. In the present work, trietylenediamine (TEDA) is used for the first time as catalyst and stabilizer for resin polymer/carbon spheres synthesis.

A non-exhaustive literature table gathering several synthesis 10 conditions (type of precursors, solvents, catalysts, synthesis temperature and time) is provided is Table S1(Supporting Information) in order to illustrate these points ${ }^{20-22 ; 25-36}$. Although, efforts have been committed to use green carbon precursors, low synthesis temperatures, aqueous solvents or shorter synthesis 15 periods ${ }^{14 ; 34 ; 35}$, no synthesis methods gathering all these positive requirements have been reported yet. Moreover, the synthesis mechanisms are rarely studied although they may shed light in the understanding of the formation of such structures and in the design of materials with improved characteristics.

Therefore, we propose a simple, fast and green synthesis strategy to design carbon spheres with controlled particle shape and size. The synthesis involves the use of green resins precursors and TEDA catalyst dissolved in water at room temperature followed 25 by a short aging periods which allows to obtain monodisperse polymer resin and carbon spheres. The particle size can be tuned from $500 \mathrm{~nm}$ to $10 \mu \mathrm{m}$ by varying the synthesis time or molar ratio between the resin and the catalyst. The synthesis mechanism is studied by coupling ${ }^{13} \mathrm{C}$ and ${ }^{1} \mathrm{H}$ NMR spectroscopy, TPD-MS 30 and XPS analysis.

\section{MATERIALS AND METHODS}

\subsection{Chemicals}

35 Phloroglucinol (1,3,5-benzentriol, $\left.\mathrm{C}_{6} \mathrm{H}_{6} \mathrm{O}_{3}\right)$, glyoxylic acid monohydrate $\left(\mathrm{C}_{2} \mathrm{H}_{2} \mathrm{O}_{3} \cdot \mathrm{H}_{2} \mathrm{O}\right)$ and triethylenediamine, TEDA $\left(\mathrm{C}_{6} \mathrm{H}_{12} \mathrm{~N}_{2}\right.$, also called 1,4-Diazabicyclo [2.2.2] octane or $\mathrm{DABCO}$ ) were purchased from Sigma-Aldrich and used as received without any further purification.

\section{${ }_{40}$ 2.2. Material Synthesis}

The polymer and carbon porous materials were synthesized via a modified Stöber method ${ }^{20}$. However, compared to literature, our synthesis involves green precursors, water solvent and room temperature conditions, most of the works being performed under 45 hydrothermal conditions (see Table S1, Supporting Information).

Typically, phloroglucinol $(0.82 \mathrm{~g})$ and glyoxylic acid $(0.72 \mathrm{~g})$ were dissolved in water $(40 \mathrm{~mL})$ at room temperature $\left(25^{\circ} \mathrm{C}\right)$ and ambient pressure, followed by the addition of TEDA $(0.36 \mathrm{~g})$ under stirring. The obtained solution was left aging in static 50 conditions (no stirring) for $24 \mathrm{~h}$ at $25^{\circ} \mathrm{C}$, a phase separation occurs and the upper layer solution is discarded while the solid polymer product is recovered and dried. In some cases, centrifugation was used to recover the polymer spheres having small sizes.

${ }_{55}$ Subsequently, a thermopolymerisation at $80^{\circ} \mathrm{C}$ for one night followed by another one at $150^{\circ} \mathrm{C}$ was performed to cross-link the polymer resin framework in the material. The obtained materials were pyrolysed at $600^{\circ} \mathrm{C}\left(2^{\circ} \mathrm{C} / \mathrm{min}\right)$ under inert atmosphere $(\mathrm{Ar})$ for 1 hour.

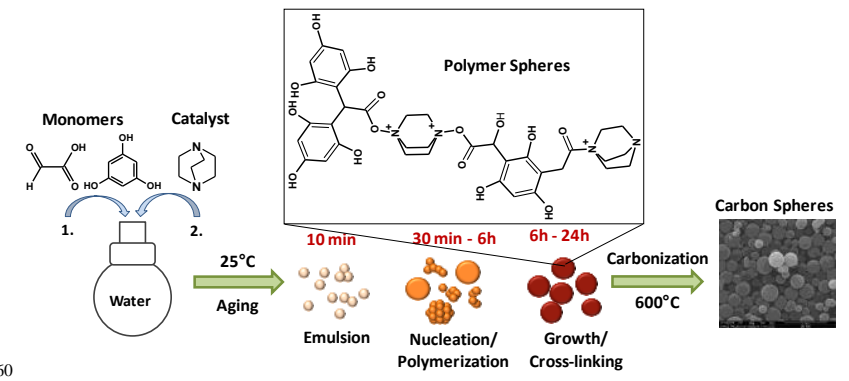

Figure 1: Schematic illustration of the synthesis of polymer and carbon spheres using green precursors and conditions.

The pyrolysis was as well performed on the as- synthesized polymer spheres (without thermopolymerization step at ${ }_{65} 80 / 150^{\circ} \mathrm{C}$ ) in order to evaluate the necessity of such step. A schematic representation of main synthesis steps is provided in Figure 1 and Figure S1 (Supporting Information).

The influence of several parameters on the particle size and morphology was investigated. Only one parameter was changed 70 on one time while keeping the others unmodified. The water volume investigated was: 10,40 and $400 \mathrm{~mL}$, the TEDA amount was: $0.09,0.18,0.36$ and $0.72 \mathrm{~g}$ while the synthesis time was: 30 min, $1 \mathrm{~h}, 3 \mathrm{~h}, 6 \mathrm{~h}$ and $24 \mathrm{~h}$.

\subsection{Material Characterization}

75 The materials morphology was evaluated by scanning electron microscopy (SEM) analysis using a FEI Quanta 400 scanning electron microscope. The particle size was measured using the SEM images and ImageJ software. The textural properties of the materials were investigated with a Micromeritics ASAP 2420

80 instrument using $\mathrm{N}_{2}$ adsorbate at $-196{ }^{\circ} \mathrm{C}$. Prior to the analysis, the samples were out-gassed overnight in vacuum at $300^{\circ} \mathrm{C}$ on the degassing port followed by $4 \mathrm{~h}$ out-gassing on the analysis port ${ }^{37}$. The BET (Brunauer-Emmett-Teller) surface area (SSA) was calculated from the linear plot in the relative pressure range of ${ }_{85}$ 0.01-0.05 while the micropore volume ( $\mathrm{V}_{\text {micro }}$ ) was determined using the Dubinin-Radushkevich (DR) equation. The total pore volume was obtained at relative pressure $\mathrm{P} / \mathrm{P}_{0}$ of 0.99 . The pore size distributions (PSD) were determined from the adsorption branch of nitrogen isotherms using the NLDFT standard slit pore 90 model for carbon materials implemented in SAIEUS software (Micromeritics) ${ }^{38 ; 39}$.

The polymer resin structure was studied by solid-state ${ }^{13} \mathrm{C}$ and ${ }^{1} \mathrm{H}$ magic angle spinning (MAS). NMR spectra were obtained at a frequency of $100.6 \mathrm{MHz}, 400.13 \mathrm{MHz}$ respectively on a Bruker ${ }_{95}$ Avance 400 NMR spectrometer. X-ray photoelectron spectroscopy (XPS) was performed with a VG Scienta SES 200-2 spectrometer equipped with a monochromatized $\mathrm{Al} \mathrm{K \alpha} \mathrm{X}$-ray source $(1486.6 \mathrm{eV})$ and a hemispherical analyzer. The pass energy was $100 \mathrm{eV}$. Thermo-gravimetric analysis (TGA) was 100 used to study the mass loss during the polymer spheres carbonization by heating with $2^{\circ} \mathrm{C} \mathrm{min}{ }^{-1}$ up to $900^{\circ} \mathrm{C}$ under nitrogen (METTLER-TOLEDO TGA 851e). The type of species evolved during the carbonization of polymer resin were analyzed by temperature programmed desorption coupled with mass 105 spectrometry ${ }^{40 ; 41}$. A small quantity of cured resin $(\sim 5 \mathrm{mg})$ was introduced in a quartz tube place inside of a furnace and heattreated in vacuum up to $950^{\circ} \mathrm{C}$. The gases evolved during the heating process were continuously detected by a mass spectrometer. 


\section{RESULTS AND DISCUSSION}

Polymer and carbon spheres were prepared by a facile and green synthesis approach. Phloroglucinol and glyoxylic acid were dissolved in water followed by the addition of TEDA. A colorless 5 solution is obtained which turned rapidly into a turbid one (few minutes later). After $30 \mathrm{~min}$ of reaction a solid product is observed on the bottom of the balloon (Figure 2) and its quantity increases with the increase of the reaction time. This is accompanied as well by the modification of the product color 10 from pale yellow $(<1 \mathrm{~h})$, to orange $(3-6 \mathrm{~h})$ and red-brown $(24 \mathrm{~h})$ suggesting more advance polymerization and cross-linking between the precursors with the reaction time proceeding.

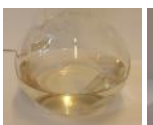

$0 \mathrm{~min}$

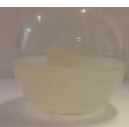

$10 \mathrm{~min}$

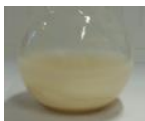

1h

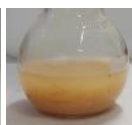

$3 \mathrm{~h}$

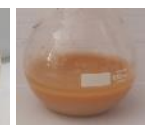

$6 \mathrm{~h}$

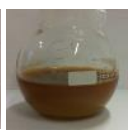

$24 \mathrm{~h}$
Figure 2: Photos of solution evolution during the time.

15 The recovered phenolic-resin polymer was thermopolymerized and thermally decomposed at $600^{\circ} \mathrm{C}$ to obtain the carbon materials. Figure 3 shows the evolution of carbon morphology with the synthesis time. In the first stages of the synthesis (10 to $30 \mathrm{~min}$ ) spherical particles with narrow uniform size of about 500 $20 \mathrm{~nm}$ are formed (Figure 3a-b). As the reaction progresses (1 to $6 \mathrm{~h}$ ), these particles tend to merge forming bigger particles with sizes of $\sim 3-4 \mu \mathrm{m}$ as seen in the in-set of Figure 3d. Therefore, agglomerated small particles and large particles coexist (Figure $3 \mathrm{c}-\mathrm{e})$. For time periods longer than $6 \mathrm{~h}$, mostly large individual ${ }_{25}$ particles with uniform shape and size are obtained (Figure 3e-f).

LaMer mechanism ${ }^{42}$ can be considered to explain the formation of the spheres. This involves nucleation of particles and a growth step. The nucleation proceeds with constant monomer concentration until the monomer concentration falls below the 30 critical level of nucleation (supersaturation level) and the nucleation ends. The resulting nuclei grow uniformly by diffusion of solutes toward the particle surfaces until the final size is attained ${ }^{42}$. This mechanism seems to not be valid in this case, in agreement with other works ${ }^{43 ; 44}$ where the particles prepared are 35 the result of aggregation of much smaller subunits rather than continuous growth by diffusion of species from the solution towards the surfaces of nuclei. A broad range of size distribution is observed during the growth step, indicating the occurrence of several nucleation events ${ }^{45}$. The final particle size uniformity 40 could be achieved through a self-sharpening growth process where the small particles grow more rapidly than the larger ones.

The influence of the amount of TEDA on the size and shape of carbon spheres was investigated. The TEDA play a double role in the synthesis, i.e., stabilizer in the formation of the particles and 45 nitrogen source to incorporate heteroatoms in the particles. For TEDA amounts smaller than $0.09 \mathrm{~g}$ (Figure 4a), the particle shape is irregular and the particles tend to merge to form agglomerates. Between 0.18 and $0.36 \mathrm{~g}$ of TEDA (Figure $4 \mathrm{~b}-\mathrm{c}$ ), the particles present smooth and homogeneous spherical shape and the size 50 slightly increases with the amount of TEDA but they become more homogenous in size.
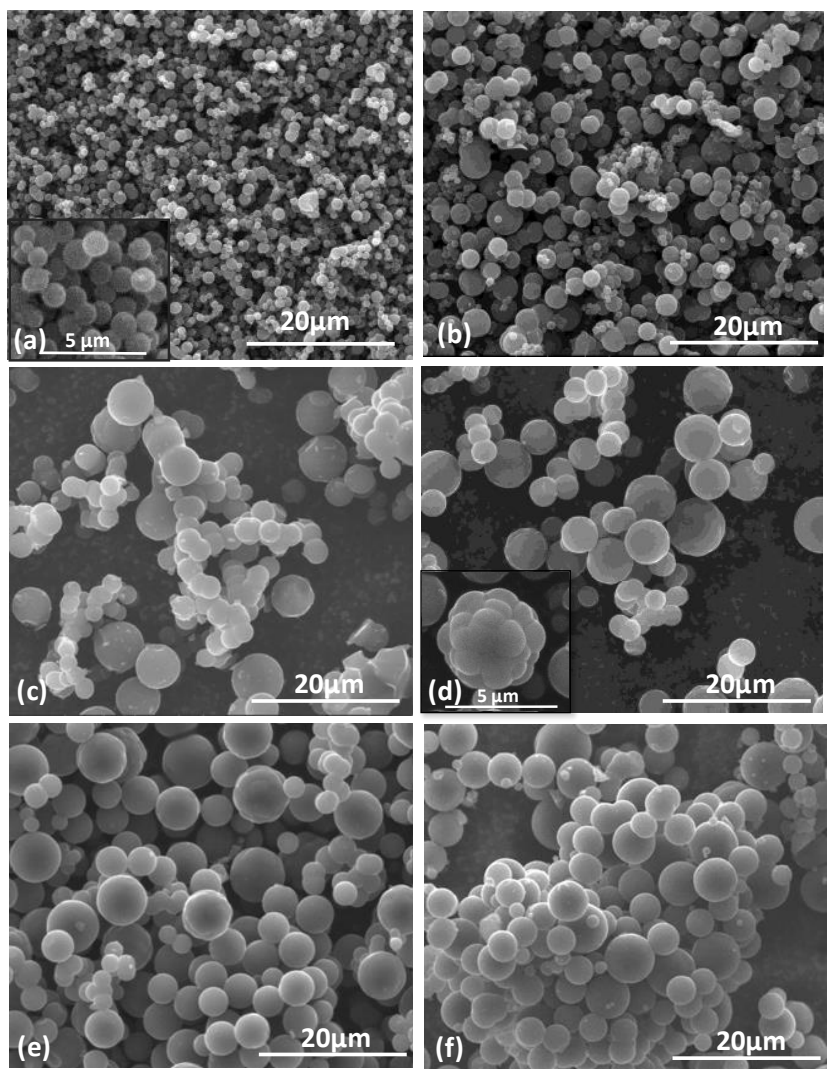

Figure 3: SEM images of carbon spheres obtained using different synthesis times: (a) $10 \mathrm{~min}$, (b) $30 \mathrm{~min}$, (c) $1 \mathrm{~h}$, (d) 3h, (e) $6 \mathrm{~h}$ and 55 (f) $24 \mathrm{~h}$; (TEDA quantity: $0.36 \mathrm{~g}$, water volume: $40 \mathrm{~mL}$ ).
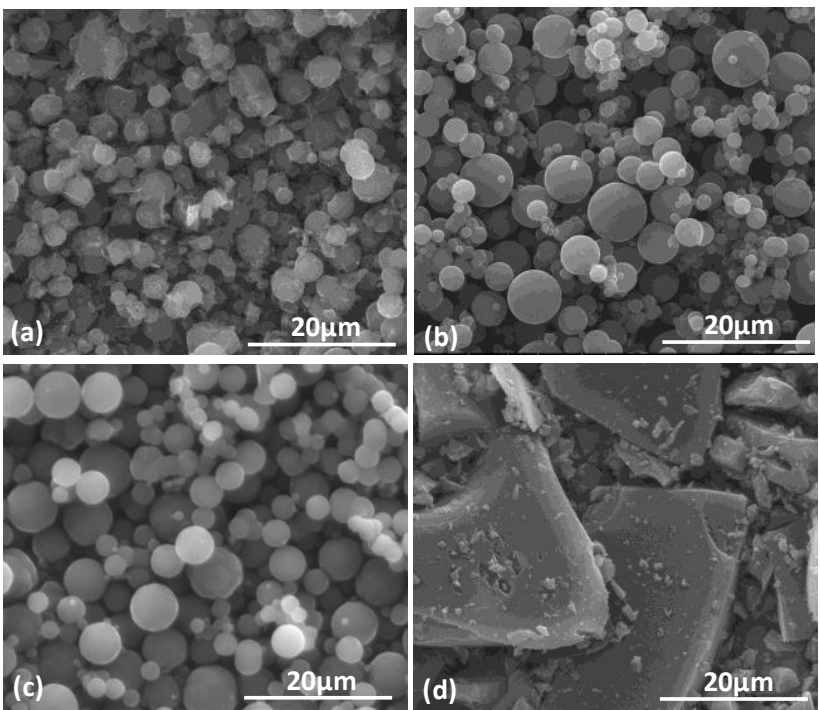

Figure 4: SEM images of carbon spheres obtained using different amounts of TEDA: (a) $0.09 \mathrm{~g}$, (b) $0.18 \mathrm{~g}$, (c) $0.36 \mathrm{~g}$ and (d) $0.72 \mathrm{~g}$; (water amount: $40 \mathrm{~mL}$, synthesis time : $24 \mathrm{~h}$ ).

60 To better understand the modification of carbon morphology with the TEDA amount, the $\mathrm{pH}$ of the solution $v s$. TEDA amount was monitored (see Figure S2, Supporting Information). With the increase of the amount of TEDA form $0.09 \mathrm{~g}$ to $0.72 \mathrm{~g}$, the $\mathrm{pH}$ significantly increases from 0 to $3.5-4$. Therefore, for highly 65 acidic conditions 0 to 1 , irregular and agglomerated spheres are formed probably due to the insufficient quantity of positive nitrogen charges delivered by the TEDA at the external part of 
the particles. Such charges, localized at the external part of the resin allow to stabilize the morphology and to avoid the agglomeration of the particles.

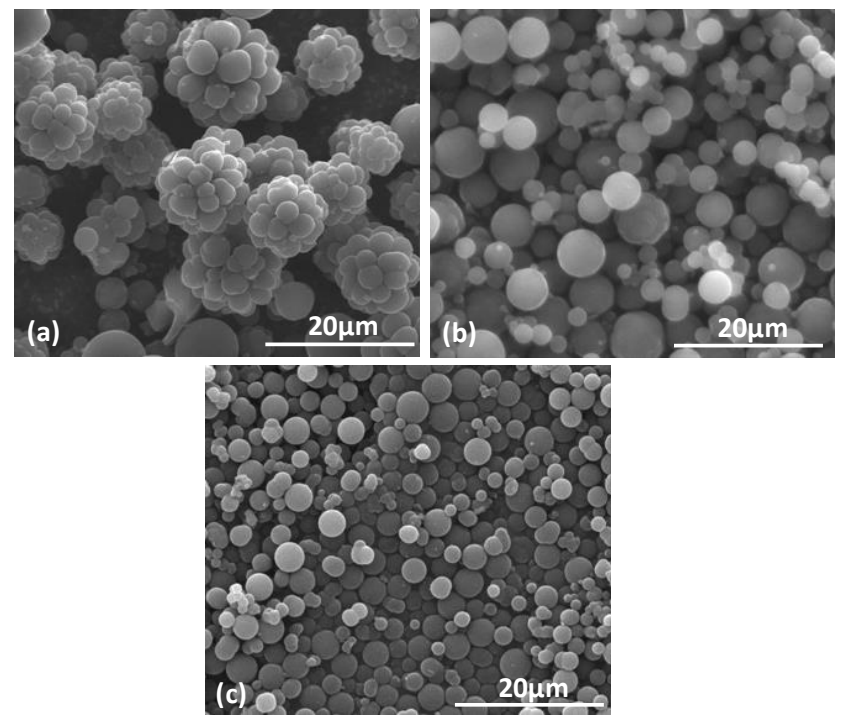

5 Figure 5: SEM images of carbon spheres obtained using different water volumes: (a) $10 \mathrm{~mL}$, (b) $40 \mathrm{~mL}$ and (c) $400 \mathrm{~mL}$; (TEDA quantity: $0.36 \mathrm{~g}$, synthesis time: $24 \mathrm{~h}$ ).

For $\mathrm{pH}$ values higher than 3 , no spheres are formed. This could 10 be related to the negative effect of such $\mathrm{pH}$ on the polymerization of phloroglucinol with glyoxylic acid and on the $\mathrm{H}^{+}$bonding of the resin with the TEDA. As a result, the $\mathrm{pH}$ interval range from 1 to 2.5 seems the most convenient one to form uniform spherical particles.

15 The impact of the solvent amount on the sphere formation was evaluated using 10, 40 and $400 \mathrm{~mL}$ of water. As noticed in Figure 5 , such parameter influences both the morphology and the size of the particles. At low water volumes $(10 \mathrm{~mL})$, the particles exhibit a flower-like morphology with average sizes of about $10 \mu \mathrm{m}$. The 20 flower particles are composed of "petals" of quasi-spherical particles with $2-3 \mu \mathrm{m}$ of diameter. When the volume of water is increased to $40 \mathrm{~mL}$, the particles become spherical and their diameter decreases to 5-7 $\mu \mathrm{m}$ (Figure $5 \mathrm{~b}$ ). Further increase in the amount of water to $400 \mathrm{~mL}$ has an effect only on the particle size, 25 which reduces to $2-4 \mu \mathrm{m}$. The decrease of the particle size with the increase of the water content in a mixture of ethanol/water has been reported by other authors. This behavior may be induced by the decrease of surface tension of the solution, resulting in smaller primary emulsion droplets and finally smaller particle 30 spheres. The formation of carbon flowers may be a result of a saturation of solution with precursors.

The textural properties of the carbon spheres were investigated and typically nitrogen adsorption/desorption isotherms and the pore size distribution are shown in Figure 6.

35 The isotherms are of type I (Figure 6a), characterized by an important increase in nitrogen adsorption volume at low relative pressures $\left(\mathrm{P} / \mathrm{P}_{0}<0.1\right)$ indicating the formation of microporous carbon spheres and a plateau which tend to increase between 0.1 and 1, suggesting the existence of larger micropores. This is in 40 line with the pore size distribution showing mainly uniform pore size centered around $0.6 \mathrm{~nm}$ (Figure 6b) and some larger micropores comprised between 0.9 and $1.6 \mathrm{~nm}$. The specific surface area and the total pore volume are ranged between 415 and $490 \mathrm{~m}^{2} \cdot \mathrm{g}^{-1}$ and $0.19-0.23 \mathrm{~cm}^{3} \cdot \mathrm{g}^{-1}$, respectively (Table 1 ).
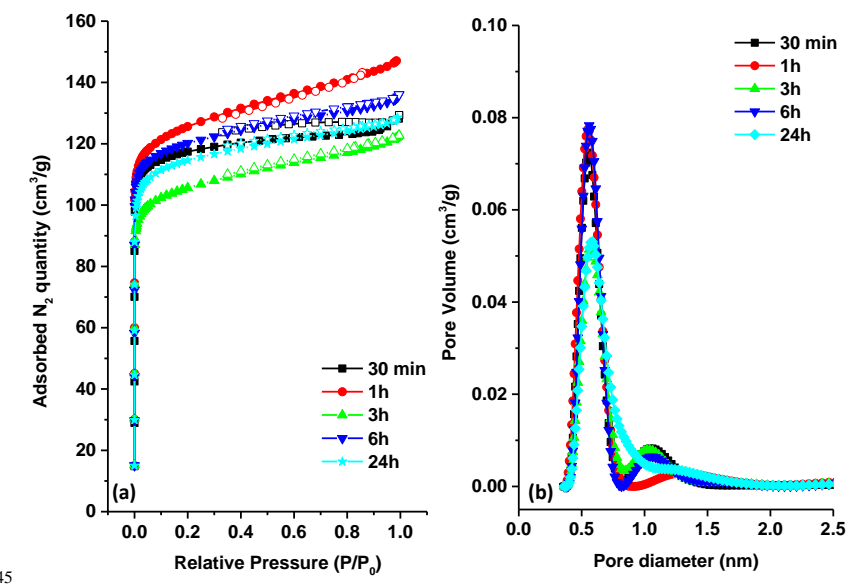

Figure 6: (a) $\mathrm{N}_{2}$ adsorption/desorption isotherms and (b) their corresponding NLDFT pore size distribution of carbon spheres synthesized under different time periods conditions (TEDA amount: $0.36 \mathrm{~g}$, water amount: $40 \mathrm{~mL}$, synthesis time: $6 \mathrm{~h}$ ).

50 Table 1: Textural properties of carbon materials synthesized under different experimental conditions.

\begin{tabular}{c|c|c|c}
\hline Materials & $\mathbf{S S A}, \mathbf{~ m}^{\mathbf{2}} \cdot \mathbf{g}^{-1}$ & $\mathbf{V t}, \mathbf{~ c m}^{\mathbf{3}} \cdot \mathbf{g}^{-\mathbf{1}}$ & $\mathbf{V}_{\text {micro }}, \mathbf{c m}^{\mathbf{3}} \cdot \mathbf{g}^{\mathbf{- 1}}$ \\
\hline 30min & 466 & 0.20 & 0.17 \\
\hline $\mathbf{1 h}$ & 490 & 0.23 & 0.20 \\
\hline 3h & 415 & 0.19 & 0.15 \\
\hline $\mathbf{6 h}$ & 471 & 0.21 & 0.18 \\
\hline $\mathbf{2 4 h}$ & 452 & 0.21 & 0.19
\end{tabular}

The formation mechanism of polymer and carbon spheres derived from phloroglucinol-glyoxylic acid resin in the presence of TEDA was never studied and is worth to be investigated. For this ${ }_{55}$ aim, the NMR technique was employed to determine the structure of the resins, XPS to study its composition, while the thermal analyses (TGA and TPD-MS) were employed to understand the decomposition of polymer resin spheres and its transformation into carbon spheres.

${ }_{60}^{60}$ Figure 7 shows the ${ }^{13} \mathrm{C}$ and ${ }^{1} \mathrm{H}$ CP-MAS (cross-polarization magic angle spinning) NMR spectra of the as-synthesized polymer resins spheres at $25^{\circ} \mathrm{C}$, thermopolymerized at $80^{\circ} \mathrm{C}$ and $150^{\circ} \mathrm{C}$, respectively. At $25^{\circ} \mathrm{C}$, the ${ }^{13} \mathrm{C}$ spectra of polymer spheres exhibit several peaks placed at 178, 154, 106, 96, 44 and $38 \mathrm{ppm}$ 65 corresponding to the carbon atoms involved in different moieties of phenolic resins formed by the polymerization reactions between the phloroglucinol and glyoxylic acid in the presence of TEDA. Except the peak from $44 \mathrm{ppm}$, all the other peaks were observed belong to phloroglucinol/glyoxylic acid resins and 70 described in detail in our previous works ${ }^{21,24}$. For clarity reasons they are reported in the in-set of the Figure 7a and described briefly herein.

The peak from $176 \mathrm{ppm}$ corresponds to carbon atoms of carboxylic acid group of glyoxylic acid or its derivates. The two 75 peaks placed at $154 \mathrm{ppm}$ and $96 \mathrm{ppm}$ are associated to carbon 
atoms in phloroglucinol, i.e., unsaturated aromatic carbons bonded with $\mathrm{OH}$ group (154 ppm) and to the $\mathrm{CH}$ unsaturated bond in the phenyl ring (96 ppm), respectively.

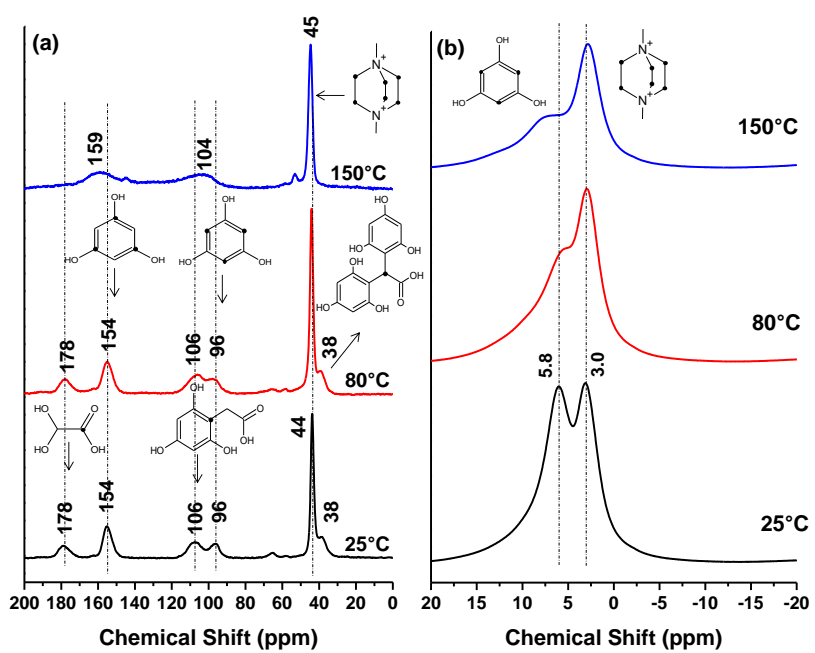

${ }_{5}$ Figure 7: ${ }^{13} \mathrm{C}$ and ${ }^{1} \mathrm{H}$ NMR spectra for phenolic resin polymer spheres as synthesized at $25^{\circ} \mathrm{C}$ and thermo-polymerized at $80^{\circ} \mathrm{C}$ and subsequently at $150^{\circ} \mathrm{C}$ (TEDA amount: $0.36 \mathrm{~g}$, water amount: $40 \mathrm{~mL}$, synthesis time: $6 \mathrm{~h})$.

The presence of those peaks indicates some un-reacted 10 phloroglucinol and glyoxylic acid at this stage of reaction $\left(25^{\circ} \mathrm{C}\right)$. However, a part of phloroglucinol reacted with glyoxylic acid by an electrophilic aromatic substitution mechanis 21,24 forming the trihydroxy-phenylacetic acid, identified in NMR by the peak placed at $105 \mathrm{ppm}$. The small peak from $38 \mathrm{ppm}$ indicates further 15 cross-linking of trihydroxy-phenylacetic acid with phloroglucinol via different mechanisms, with the formation of carboxylic acid and/or lactone bridges between the phloroglucinol rings ${ }^{46}$. The most intense peak noticed at $44 \mathrm{ppm}$ is assigned to carbon atoms bonded with positively charged nitrogen of TEDA molecule.

20 TEDA may link to phloroglucinol/glyoxylic acid resin via oxygen coming from trihydroxy phenylacetic acid as schematically shown in the in-set of Figure 1 and 7. This is evidence that the TEDA is integrated in the backbone of phenolic resin.

With the increase of the temperature at 80 and $150^{\circ} \mathrm{C}$, we observe 25 progressive evolution of the glyoxylic acid and phloroglucinol peaks towards unique peaks. At $80^{\circ} \mathrm{C}$, the 106 and $96 \mathrm{ppm}$ resonance peaks become closer and merge to one single peak at $150^{\circ} \mathrm{C}$, suggesting highly substituted phenyl ring and higher cross-linking. In the same way the 178 and $154 \mathrm{ppm}$ peaks related 30 to phloroglucinol and glyoxylic acid did not progress very much at $80^{\circ} \mathrm{C}$, but at $150^{\circ} \mathrm{C}$ they merge as well into a single peak with intermediate position, i.e., $159 \mathrm{ppm}$. Therefore, at $150^{\circ} \mathrm{C}$, all initial precursors reacted to form a cross-linked phloroglucinol/glyoxylic acid/TEDA resin.

35

The ${ }^{1} \mathrm{H}$ NMR exhibit mainly two peaks at $25^{\circ} \mathrm{C}$, at 5.8 and 3.0 ppm which are assigned to protons involved in phenyl ring of phloroglucinol and in TEDA, respectively. By increasing the temperature to $80^{\circ} \mathrm{C}$ and $150^{\circ} \mathrm{C}$, the $5.8 \mathrm{ppm}$ peak intensity 40 significantly decreases indicating highly substituted phloroglucinol and better cross-linking, while the $3.0 \mathrm{ppm}$ peak become wider indicating protons involved in rigid (cross-linked) structures. These observations are in good agreement with the ${ }^{13} \mathrm{C}$
NMR results showing increase cross-linking with the increase of 45 the temperature.

The surface chemistry of thermopolymerized polymer spheres and of the derived carbon spheres was analyzed by XPS.
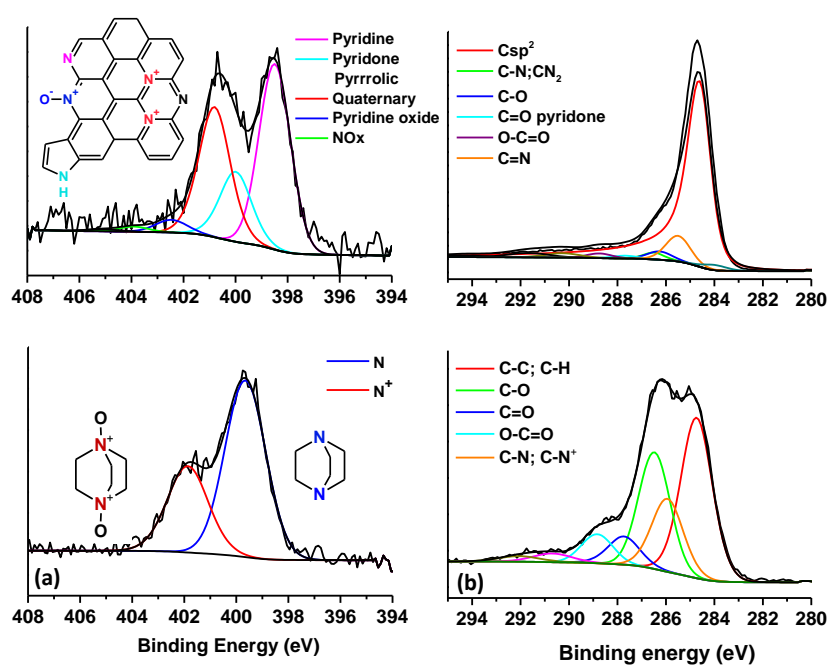

Figure 8: XPS spectra of polymer spheres thermo-polymerized 50 (down) and derived carbon spheres (up): N1s (a) and C1s (b) high resolution deconvoluted peaks; in-set: nitrogen groups (TEDA amount: $0.36 \mathrm{~g}$, water amount: $40 \mathrm{~mL}$, synthesis time: $6 \mathrm{~h}$ ).

The XPS survey spectra (not shown here) revealed that the amounts of nitrogen, oxygen and carbon before carbonization are 55 5.3, 22.7 and 72.0 at.\%. After carbonization the amounts of nitrogen and oxygen decreases to 3.1 and 7.7 at.\%, respectively, while the carbon amount increases to 87.9 at. $\%$.

Figure 8a shows the high-resolution N1s XPS spectra. For polymer spheres the peak show mainly two contributions at 400 ${ }_{60} \mathrm{eV}$ and $402 \mathrm{eV}$ corresponding to $\mathrm{N}$ atoms involved in TEDA and positively charges $\mathrm{N}^{+}$in TEDA, respectively, involved in the phenolic resin (Fig. 7a down). After the thermal treatment of polymer spheres, the obtained carbon spheres present a N1s peak which was deconvoluted into five main components peaks i.e., ${ }_{65}$ pyridinic nitrogen $(398 \mathrm{eV})$, pyrrolic nitrogen $(400 \mathrm{eV})$, quaternary nitrogen $(401 \mathrm{eV})$, pyridine oxide $(403 \mathrm{eV})$ and nitrogen oxides (404 eV), as schematically shown in the in-set of Fig. 7a (up). This result confirms the incorporation of nitrogen groups into the polymer and carbon framework.

70 The high-resolution C1s XPS spectra (Figure 8b) of thermopolymerized polymer spheres show two merged peaks placed at 285 and $286 \mathrm{eV}$ which are deconvoluted into five components. The most intense peak is placed at 284.7 and is related to $\mathrm{C}-\mathrm{C}$ and $\mathrm{C}-\mathrm{H}$ bonds in polymer resin, the second 75 important contribution is placed at 286.5 and corresponds to $\mathrm{C}-\mathrm{O}$ bonds, the peak at 285.9 is related to $\mathrm{C}-\mathrm{N}$ and $\mathrm{C}-\mathrm{N}^{+}$bonds, while two other smaller contributions from 287.7 and $288.8 \mathrm{eV}$, are assigned to $\mathrm{C}=\mathrm{O}$ and $\mathrm{O}-\mathrm{C}=\mathrm{O}$ bonds. After carbonization the $\mathrm{C} 1 \mathrm{~s}$ present only one intense peak at $284.5 \mathrm{eV}$ which is assigned to 80 graphite-like sp2 carbon ${ }^{47}$. A tail of asymmetric C 1s peak at higher binding energies is originated from the presence of carbon atoms bonded to nitrogen $(\mathrm{C}=\mathrm{N}$ and $\mathrm{C}-\mathrm{N})$ and different oxygenfunctional groups $(\mathrm{C}-\mathrm{OR}, \mathrm{C}=\mathrm{O}$ and $\mathrm{O}=\mathrm{C}-\mathrm{O})$. Those oxygen groups are in less quantity than in the polymer spheres, therefore, 85 were removed during the carbonization. 
To better understand the transformation of polymer spheres into carbon spheres, thermal analysis techniques, i.e., TGA and TMDMS were employed.
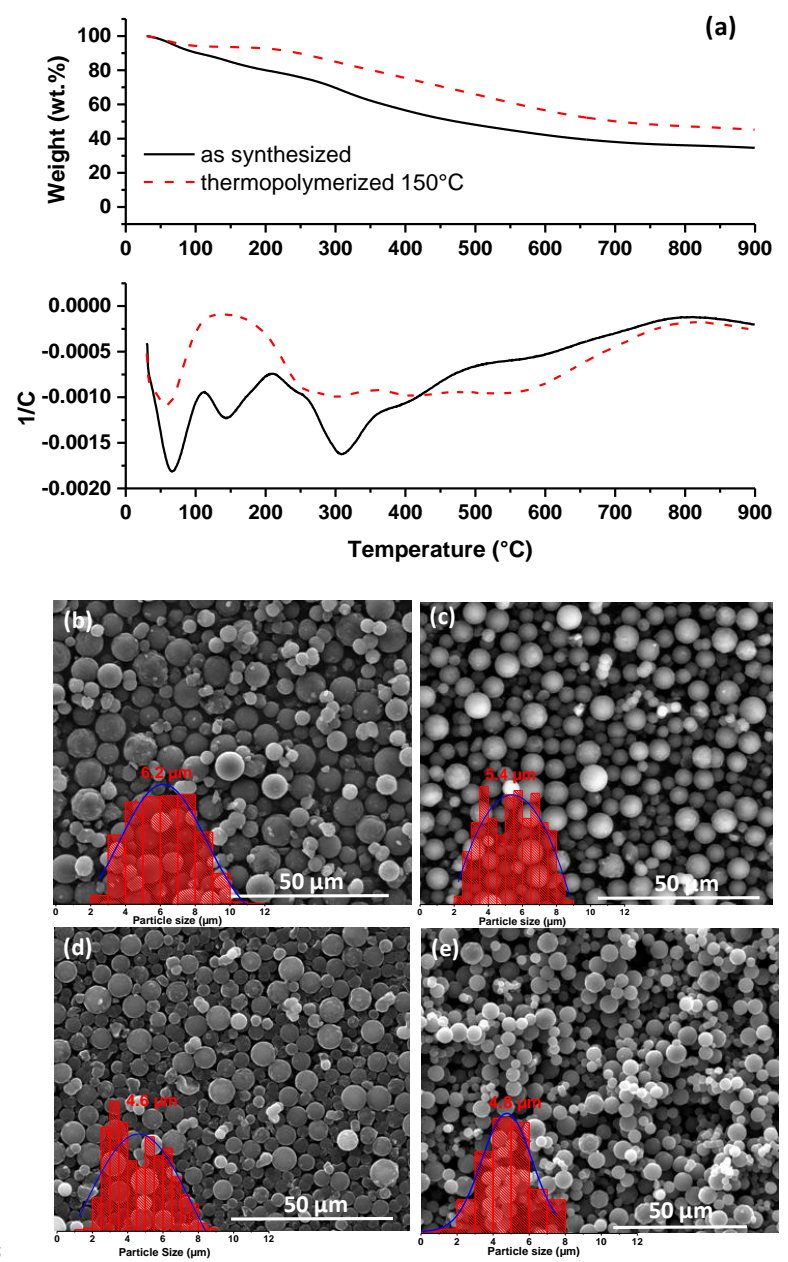

Figure 9: TGA under inert atmosphere of the as synthesized and thermopolymerized at $150^{\circ} \mathrm{C}$ polymer spheres (a); SEM pictures of as-synthesized (b) and thermopolymerized polymer spheres at $150^{\circ} \mathrm{C} \mathrm{(c)} \mathrm{and} \mathrm{their} \mathrm{corresponding} \mathrm{carbon} \mathrm{spheres} \mathrm{(d} \mathrm{and} \mathrm{e);} \mathrm{in-}$ 10 set: particle size distribution; (TEDA amount: $0.36 \mathrm{~g}$, water amount: $40 \mathrm{~mL}$, synthesis time: $6 \mathrm{~h}$ ).

Figure 9 shows the TGA profile under nitrogen of as-synthesized and thermopolymerized at $150^{\circ} \mathrm{C}$ polymer spheres. For the assynthesized polymer spheres, three main peaks are observed. The 15 first one is placed between 25 and $100^{\circ} \mathrm{C}$, with a maximum at $60^{\circ} \mathrm{C}$ and can be related to physisorbed water on the material. The second peak is ranged between 100 and $200^{\circ} \mathrm{C}$, with a maximum at $150^{\circ} \mathrm{C}$ which may be assigned to water or other species evolved during the polymerization/polycondensation reactions 20 between the phloroglucinol and glyoxylic acid. The third peak is located between 250 and $400^{\circ} \mathrm{C}$ with a maximum at $300^{\circ} \mathrm{C}$ and may be attributed to the decomposition of polymer resin. When the polymer spheres are thermopolymerized at $150^{\circ} \mathrm{C}$, the peak at $60^{\circ} \mathrm{C}$ related to physisorbed water is still observed but is less 25 intense while the peak at $150^{\circ} \mathrm{C}$ is not any longer visible, indicating the well cross-linking of the polymer spheres. The peak at $300^{\circ} \mathrm{C}$ becomes as well less defined. The yield in carbon of thermopolymerized polymer is about $55 \mathrm{wt} . \%$ at $600^{\circ} \mathrm{C}$ and 45 wt. $\%$ at $900^{\circ} \mathrm{C}$, which is an advantage of resin precursor. The
30 morphology of the polymer spheres are well conserved, however, shrinkage of particle size during the thermopolymerization step and thermal treatment is observed (Figure 9b-e). The assynthesized polymer particles have an average size of $6.2 \mu \mathrm{m}$ (inset Figure 9b) which decreases to $5.4 \mu \mathrm{m}$ during the 35 thermopolymerization step $(\sim 13 \%$ shrinkage, Figure $9 \mathrm{c})$ and to $4.8 \mu \mathrm{m}$ during the thermal treatment $(\sim 12 \%$ shrinkage, Figure $9 \mathrm{e}$ ), therefore, a total of $25 \%$ of shrinkage. These observations are in good agreement with other works $20 ; 25 ; 28 ; 29 ; 34$ where shrinking of polymer particle between 12 and $30 \%$ was observed during 40 the carbonization step. The shrinkage rate was found to depend by the polymer composition, structure and thermal annealing conditions. It is worth to note that, if the as-synthesized polymer particles are directly carbonized, the average particle size decreases to $4.6 \mu \mathrm{m}$ ( $26 \%$ shrinkage, Figure $9 \mathrm{~d})$, thus, the final 45 shrinkage of the particle and their size is rather similar as in the case of thermopolymerized particles.

Therefore, the obtainess of carbon spheres is not conditioned by the thermopolymerization step, even if such step is performed in most of previous works 20;21;25;29;30;32;33. The removal of the

50 thermopolymerization step represents in this case an advantage in term of synthesis time and energy consumption reduction.

More insights on the evolved chemical species during the transformation of polymer spheres into carbon spheres were assessed by TPD-MS. By such technique, the polymer spheres 55 are heat treated under vacuum and the evolved species are monitored by a mass spectrometer. Several species, i.e., $\mathrm{CO}(\mathrm{m} / \mathrm{z}$ $=28), \mathrm{CO}_{2}(\mathrm{~m} / \mathrm{z}=44), \mathrm{H}_{2}(\mathrm{~m} / \mathrm{z}=2), \mathrm{CH}_{4}(\mathrm{~m} / \mathrm{z}=16)$ and $\mathrm{HN}_{3}(\mathrm{~m} / \mathrm{z}$ $=17)$ are calibrated, allowing their quantitative determination during the material decomposition. Figure 10a, shows the ${ }_{60}$ evolution of the experimental pressure (pressure induced during the sample heating due to the evolved gases) and the calculated pressure (calculated taking into consideration only the calibrated gases above mentioned) with the temperature. We note mainly two peaks placed around $300^{\circ} \mathrm{C}$ and $550^{\circ} \mathrm{C}$ for both pressures.
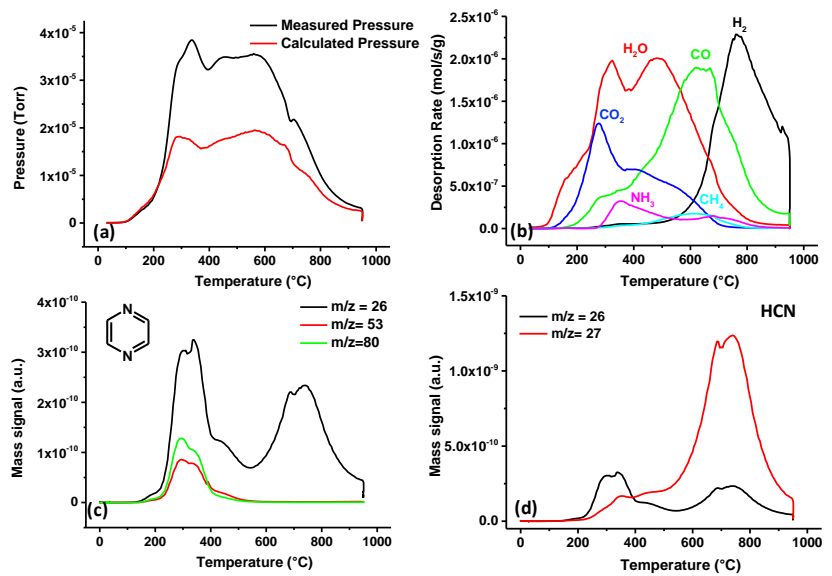

Figure 10: TPD-MS desorption spectra of polymer spheres thermo-polymerized at $150^{\circ} \mathrm{C}$ (a) evolution of measured and calculated pressures, (b) desorption profiles of calibrated gases and (c), (d) desorption profiles of non-calibrated gases. (TEDA 70 amount: $0.36 \mathrm{~g}$, water amount: $40 \mathrm{~mL}$, synthesis time: $6 \mathrm{~h}$ ).

The experimental pressure curve is higher in intensity than the calculated pressure, implying the evolvement of supplementary gaseous species from the material during heating than the calibrated ones. For more details, the calibrated gases desorption 
profiles $v s$. the temperature can be seen in Figure 10b. The most intense peaks are corresponding to $\mathrm{H}_{2} \mathrm{O}, \mathrm{CO}, \mathrm{CO}_{2}$ and $\mathrm{H}_{2}$, while smaller contribution of $\mathrm{CH}_{4}$ and $\mathrm{NH}_{3}$ is detected as well.

The $\mathrm{CO}_{2}$ peak is very large, comprised between 200 and $600^{\circ} \mathrm{C}$. 5 The $\mathrm{CO}_{2}$ formation is usually attributed to the decomposition of acidic groups such as carboxylic $\left(\sim 200-300^{\circ} \mathrm{C}\right)$ and/or anhydride groups $\left(>300^{\circ} \mathrm{C}\right)^{41 ; 48}$. The latest one decomposition is accompanied by the evolution of $\mathrm{CO}$ gas as well. The $\mathrm{CO}$ peak is placed between 200 and $800^{\circ} \mathrm{C}$ and corresponds at low 10 temperature to the decomposition of acidic groups such anhydrides as mentioned above, and at higher temperatures to the decomposition of more basic groups such as phenol, quinones, lactones and ethers $37 ; 48 ; 49$.

The water peak presents two maxima at $300^{\circ} \mathrm{C}$ and $450^{\circ} \mathrm{C}$ which 15 may be related to the in-situ reactions between functional groups during the TPD-MS experiment. The first peak, may be linked to the desorption of water formed due to the reaction between two neighbor carboxylic groups $(-\mathrm{COOH})$ of glyoxylic acid with the formation of anhydrides groups which subsequently decomposes 20 at higher temperature $\left(450^{\circ} \mathrm{C}\right)$ with the formation of water and concomitantly of $\mathrm{CO}$ and $\mathrm{CO}_{2}$. This suggests the cross-linking and the further decomposition (carbonization) of polymer spheres. A high intense peak of $\mathrm{H}_{2}$ is noticed for temperatures higher than $600^{\circ} \mathrm{C}$ due to the structural organization of carbon 25 through $\mathrm{C}-\mathrm{H}$ bond cleavage. Smaller amounts of $\mathrm{CH}_{4}$ and $\mathrm{NH}_{3}$ are released during this process but in smaller extent.

Besides these gases, other species are observed by MS. Firstly, we investigate the existence of mass signals coming from TEDA (Figure S3a, Supporting Information), and no peaks related to this 30 molecule were found. However, peaks with $\mathrm{m} / \mathrm{z}=26,53$ and 80 were detected (Figure 10c) which were found to correspond to pyrazine (Figure S3b, Supporting Information). This means that TEDA transformed into pyrazine at around $200^{\circ} \mathrm{C}$, by eliminating ethane molecules, observed as well at this temperature is small 35 quantities. A closer look to the peaks of pyrazine (Figure 10c) show the presence of a secondary peak for the mass $\mathrm{m} / \mathrm{z}=26$ at around $700^{\circ} \mathrm{C}$, which do not correspond to pyrazine but rather to the hydrogen cyanide $(\mathrm{HCN})$. This compound present 2 main mass signals at $\mathrm{m} / z=26$ and $\mathrm{m} / z=27$ (Figure S3c, Supporting

40 Information), and it can be clearly confirmed with the peak at $\mathrm{m} / \mathrm{z}$ $=27$, that the peak at $600^{\circ} \mathrm{C}$ belongs to $\mathrm{HCN}$. Therefore, the removal of nitrogen from the carbon structure when increasing the temperature well above $600^{\circ} \mathrm{C}$ occurs.

\section{Conclusions}

45 A simple and sustainable synthesis approach to design polymer and carbon spheres was developed. Such approach employs green concepts, i.e., green precursors and catalysts, water as solvent and room temperature conditions, therefore, easily scalable and answering to practical and industrial requirements. Particles with 50 uniform shape and size that could be tuned between $500 \mathrm{~nm}$ and $10 \mu \mathrm{m}$ were obtained by varying the synthesis conditions. The surface charges, surface tension and polymerization rate are some of the key factors influencing the particle size and morphology. The carbon particles are microporous and exhibit specific surface 55 areas up to $490 \mathrm{~m}^{2} \cdot \mathrm{g}^{-1}$ and nitrogen in their structure. Insights on the synthesis mechanism of polymer and carbon spheres were assessed be coupling several techniques. The structure of polymer resin spheres and its evolution with the temperature was determined by ${ }^{13} \mathrm{C}$ NMR and XPS while their decomposition
60 behavior along with the evolved species during the carbon sphere formation was monitored by TPD-MS.

The as-designed materials can be easily functionalized with other heteroatoms and/or metallic nanoparticles and further employed for a wide range of applications.

\section{Acknowledgements}

The authors thank Samar Hajjar and Gauthier Schrodj for the help provided with the XPS and TGA analyses through the technical platform of IS2M. Financial support of this work by the French

National Research Agency (ANR) project Genesis (ANR-1370 BS08-0004-02) is acknowledged.

\section{Notes and references}

Université de Strasbourg, Université de Haute Alsace, Institut de Science des Matériaux de Mulhouse, CNRS UMR 7361, 15 rue Jean Starcky, 68057 Mulhouse-France.

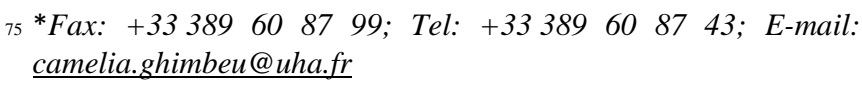

$\dagger$ Electronic Supplementary Information (ESI) available: [Synthesis steps, Evolution of $\mathrm{pH}$ with TEDA amount, and MS spectra]. See DOI: $10.1039 / \mathrm{b} 000000 \mathrm{x} /$

1 W. Li, J. Liu, D. Zhao, Nature Materials 2016, 1, 16023.

2 P. Zhang, Z. Qiao, S. Dai, Chem Commun 2015, 51, 9246.

3 H. Chang, S. Joo, P. Chanho, J Mater Chem 2007, 17, 3078.

4 L. Chuenchom, R. Kraehnert, B. M. Smarsly, Soft Matter 2012, 8, 10801.

5 J. C. Ndamanisha, L. P. Guo, Anal.Chim.Acta 2012, 747, 19.

6 T.-Y. Ma, L. Liu, Z.-Y. Yuan, Chem.Soc.Rev. 2013, 42, 3977.

7 A. Marquez-Nieto, R. Romero, A. Romero, J. Valverde, J Mater Chem 2010, 21, 1664.

8 J. Liu, N. Wickramaratne, Z. Qiao, M. Jaroniec, Nature Materials 2015, 14, 763.

9 Z. Wang, F. Li, A. Stein, Nano Lett. 2007, 7, 3223.

10 T. W. Kim, P. W. Chung, I. I. Slowing, M. Tsunoda, E. S. Yeung, V. S. Y. Lin, Nano Lett. 2008, 8, 3724.

11 Y. Fang, D. Gu, Y. Zou, Z. Wu, F. Li, R. Che, Y. Deng, B. Tu, D. Zhao, Angew.Chem.Int.Ed. 2010, 49, 7987.

12 J. Liu, T. Yang, D.-W. Wang, G. Lu, D. Zhao, S. Qiao, Nature Commun. 2013, 4, 2798.

13 K. Tekin, D. Pileidis, K. Akalin, S. Karagoz, Clean Technologies and Environmental Policy 2016, 18, 331.

14 M. M. Titirici, M. Antonietti, Chem Soc Rev 2010, 39, 103.

15 X. Sun, Y. Li, Angew.Chem.Int.Ed. 2004, 597.

16 L. Mao, Y. Zhang, Y. Hu, K. Ho, Q. Ke, H. Liu, Z. Hu, D. Zhao, J. Wang, RSC Adv. 2015, 5, 9307.

17 M. Sevilla, A. B. Fuertes, R. Mokaya, Energy Environ.Sci. 2011, 4, 1400.

18 M. Li, W. Li, S. Liu, Carbohydr Res 2011, 346, 999.

19 A. Lu, G. Hao, Q. Sun, Angew.Chem.Int.Ed. 2011, 50, 9023.

20 J. Liu, S. Qiao, H. Liu, J. Chen, A. Orpe, D. Zhao, G. Q. Lu, Angew.Chem.Int.Ed. 2011, 50, 5947.

21 N. Wickramaratne, V. Perera, J. Ralph, S. Huang, M. Jaroniec, Langmuir 2016, 29, 4032. 
22 J. Qian, M. Liu, L. Gan, P. Tripathi, D. Zhu, Z. Xu, Z. Hao, L. Chen, D. Wright, Chem Commun 2013, 49, 3043.

23 J. Zhao, W. Niu, L. Zhang, H. Cai, M. Han, Y. Yuan, S. Majeed, S. Anjum, G. Xu, Macromolecules 2013, 46, 140.

524 C. Matei Ghimbeu, L. Vidal, L. Delmotte, J.-M. Le Meins, C. Vix-Guterl, Green Chemistry 2014, 16, 3079.

25 J.-C. Song, Z.-Y. Lu, Z.-Y. Sun, J Colloid Interf.Sci. 2014, 431, 132.

26 Y.-R. Dong, N. Nishiyama, Y. Egashira, K. Ueyama, Ind Eng Chem Res 2008, 47, 4712.

27 F. Braghirolia, V. Fierro, J. Parmentier, Vidal L, P. Gadonnrixa, A. Celzard, Industrial Crops and Products 2015, 77, 364.

28 N. Wickramaratne, J. Xu, M. Wang, L. Zhu, L. Dai, M. Jaroniec, Chem Mater 2014, 26, 2820.

1529 B. Friedel, S. Greulich-Weber, Small 2006, 2, 859.

30 H. Zhou, S. Xu, H. Su, M. Wang, W. Qiao, L. Ling, D. Long, Chem Commun 2013, 49, 3763.

31 J. Yan, L. Yang, M.-F. Lin, J. Ma, X. Lu, P. Lee, Small 2013, 9, 596.

32 C. Zhang, K. B. Hatzell, M. Boota, B. Dyatkin, M. Beidaghi, D. Long, W. Qiao, E. Kumburn, Y. Gogotsi, Carbon 2014, 77, 155.

33 J. Choma, W. Fahrenholz, D. Jamiola, J. Ludwinowicz, M. Jaroniec, Micro.Mesoporous.Mater. 2014, 185, 197.

34 K. Ai, Y. Liu, C. Ruan, L. Lu, G. Lu, Advanced Materials 2013, 25, 998.

35 F. Braghirolia, V. Fierra, M. Izquierdo, J. Parmentier, A. Pizzie, L. Delmotte, F. Fioux, A. Celzard, Industrial Crops and Products 2015, 66, 282.

36 N. Wickramaratne, M. Jaroniec, Chem Commun 2014, 50, 12341.

$30 \quad 37$ C. Decaux, C. Matei-Ghimbeu, M. Dahbi, M. Anouti, D. Lemordant, F. Beguin, C. Vix-Guterl, E. Raymundo-Piñero, J.Power Sources 2014, 263, 130.

38 J. Jagiello, J. Olivier, Adsorption 2013, 19, 777.

39 J. Jagiello, J. Olivier, Carbon 2013, 55, 70.

3540 C. Matei Ghimbeu, C. Decaux, P. Brender, M. Dahbi, D. Lemordant, E Raymundo-Pinero, M. Anouti, F. Beguin, C. VixGuterl, J Electrochem.Soc. 2013, 160, A1907-A1915.

41 C. Matei Ghimbeu, R. Gadiou, J. Dentzer, D. Schwartz, C. VixGuterl, Langmuir 2010, 26, 18824.

4042 V. LaMer, R. Dinegar, J Am Chem Soc 1950, 72, 4847.

43 M. Ocana, C. Rodriguez-Clemente, J. Sema, Adv Mater 1995, 7, 212.

44 P. Calvert, Nature 1994, 367, 119.

45 G. Bogush, M. Tracy, C. Zukoski, J Non-Cryst.Solids 1988, 104, 95.

46 C. Nita, M. Bensafia, C. Vaulot, L. Delmotte, C. Matei Ghimbeu, Carbon 2016, 109, 227.

47 P. Brender, R. Gadiou, J. C. Rietsch, P. Fioux, J. Dentzer, A. Ponche, C. Vix-Guterl, Anal.Chem. 2012, 84, 2147.

5048 J. L. Figueiredo, M. F. R. Pereira, M. M. A. Freitas, J. J. M. Orfao, Carbon 1999, 37, 1379.

49 G. Moussa, C. Matei Ghimbeu, P.-L. Taberna, P. Simon, C. VixGuterl, Carbon 2016, 105, 268. 